\title{
Article
}

\section{Effects of running with minimal and conventional footwear in habitual and non-habitual users: a musculoskeletal simulation and statistical parametric mapping based approach.}

Sinclair, Jonathan Kenneth, Taylor, Paul John and Liles, Naomi Available at http://clok.uclan.ac.uk/30249/

Sinclair, Jonathan Kenneth ORCID: 0000-0002-2231-3732, Taylor, Paul John ORCID: 0000-0002-9999-8397 and Liles, Naomi (2020) Effects of running with minimal and conventional footwear in habitual and non-habitual users: a musculoskeletal simulation and statistical parametric mapping based approach. Footwear Science, 12 (1). pp. 25-38. ISSN 1942-4280

It is advisable to refer to the publisher's version if you intend to cite from the work. http://dx.doi.org/10.1080/19424280.2019.1683619

For more information about UCLan's research in this area go to http://www.uclan.ac.uk/researchgroups/ and search for < name of research Group>.

For information about Research generally at UCLan please go to http://www.uclan.ac.uk/research/

All outputs in CLoK are protected by Intellectual Property Rights law, including Copyright law. Copyright, IPR and Moral Rights for the works on this site are retained by the individual authors and/or other copyright owners. Terms and conditions for use of this material are defined in the policies page. 
Effects of running with minimal and conventional footwear in habitual and non-

habitual users; a musculoskeletal simulation and statistical parametric mapping based

\section{approach.}

\section{Jonathan Sinclair ${ }^{1}$, Paul John Taylor ${ }^{2}$ \& Naomi Liles ${ }^{1}$}

1. Centre for Applied Sport and Exercise Sciences, School of Sport and Health Sciences, Faculty of Health and Wellbeing, University of Central Lancashire.

2. School of Psychology, Faculty of Science \& Technology, University of Central Lancashire.

Keywords: Biomechanics; musculoskeletal; footwear; running, minimal footwear.

\section{Abstract}

The current investigation examined running biomechanics in minimal and conventional footwear in two groups of runners who either ran habitually in minimal footwear (habitual minimal footwear users) or habitually in conventional footwear (non-habitual minimal footwear users). We studied ten male non-habitual minimal footwear users and ten male habitual minimal footwear users, who were required to complete $\geq 35 \mathrm{~km}$ per week of training. Lower extremity joint loading was explored using a musculoskeletal simulation approach. Differences between conditions were examined using statistical parametric mapping and $2 \times 2$ mixed ANOVA. This study revealed via the strike index that minimal footwear caused a more anterior contact position in both groups (habitual: minimal $=61.68 \%$ \& conventional $=46.48 \%$ /non-habitual: minimal $=33.79 \% \&$ conventional $=22.61 \%$ ), although non-habitual runners still adopted a rearfoot strike pattern. In addition, in non-habitual users minimal footwear increased tibial accelerations (habitual: minimal $=6.35 \mathrm{~g} \&$ conventional=7.06g $/$ non-habitual: minimal=9.54g \& conventional $=8.16 \mathrm{~g}$ ), loading rates (habitual: $\operatorname{minimal}=105.44 \mathrm{BW} / \mathrm{s} \quad \&$ 
conventional $=212.57 \mathrm{BW} / \mathrm{s}$ ). Furthermore, minimal footwear decreased patellofemoral loading

in both habitual (minimal=0.28BW.s \& conventional=0.31BW.s) and non-habitual

$($ minimal $=0.26 \mathrm{BW} \cdot \mathrm{s} \&$ conventional $=0.29 \mathrm{BW} \cdot \mathrm{s})$ users. Finally, Achilles tendon loading was

larger in minimal footwear and in habitual runners (habitual: minimal=0.79BW $\cdot \mathrm{s} \&$

conventional $=0.71 \mathrm{BW} \cdot \mathrm{s} \quad /$ non-habitual: $\quad$ minimal $=0.71 \mathrm{BW} \cdot \mathrm{s} \quad \& \quad$ conventional $=0.65 \mathrm{BW} \cdot \mathrm{s})$

whereas iliotibial band strain rate was reduced in habitual (minimal $=28.32 \% / \mathrm{s} \&$

conventional $=30.30 \% / \mathrm{s})$ in relation to non-habitual (minimal $=42.96 \% / \mathrm{s} \quad \&$ conventional $=42.87 \% / \mathrm{s}$ ) users. This study highlights firstly the importance of transitioning to minimal footwear and also indicates that post transition they may be effective in attenuating the biomechanical mechanisms linked to the aetiology of many chronic injuries.

\section{Introduction}

Recreational distance running is arguably the most popular aerobic exercise modality (Lee et

al. 2014). There is a plethora of evidence indicating that running mediates significant physiological and psychological benefits (Lee et al. 2014). However, despite the physical benefits that it manifests, distance running is also associated with a high susceptibility to chronic injuries; as 19.4-79.3\% of runners will experience a pathology each year (Van Gent et al. 2007). Unfortunately, chronic pathologies are a significant barrier to training adherence in runners and lead to a substantial economic burden (Hespanhol et al. 2016). Specifically, patellofemoral pain, iliotibial band syndrome, tibial stress fractures, medial tibial stress syndrome, Achilles tendinopathy and pain secondary to hip and knee osteoarthritis are 
commonly experienced in sports medicine clinics (Taunton et al. 2002, Van Ginckel et al. 2009;

Winkelmann et al. 2016; Snyder et al. 2006).

The running shoe is the primary interface between the body and surface; as such significant developments in running shoe technology have emerged, in an attempt to mediate the incidence of chronic running pathologies (Sinclair et al. 2013a). However, since the introduction of the conventional running shoe, the rate and location of chronic running injuries has not changed, leading to the notion that technological developments in running footwear have not been successful in influencing running pathologies (Davis, 2014). This has led to the proposal that running in minimal footwear that lacks the cushioning and motion control properties associated with the conventional running shoe, may be associated with a reduced incidence of chronic running injuries (Lieberman et al. 2010; Davis, 2014). Based on this notion, several minimal footwear models are currently available commercially.

Several studies have examined differences in running biomechanics between minimal and conventional running shoes. These investigations have shown that minimal footwear alter spatiotemporal running characteristics, causing runners to adopt a more plantarflexed ankle at footstrike (Sinclair et al. 2013ab, Hollander et al. 2015), mid/forefoot strike pattern (Squadrone et al. 2015; Sinclair et al. 2019), increased stride rate (Warne et al. 2014) and reduced stride length (Sinclair et al. 2016; Sinclair et al. 2019) compared to conventional running shoes. In addition, previous comparisons of conventional and minimal footwear have also shown that minimal footwear are associated with increased vertical loading rates (Sinclair et al. 2013ab), tibial accelerations (Sinclair et al. 2013a), and effective mass (Sinclair et al. 2018a). Finally, previous work examining the effects of minimal footwear on the loads experienced by the lower extremities have revealed that minimal footwear reduces the loads experienced by the 
74 patellofemoral joint (Sinclair, 2014; Bonacci et al. 2014), but increase the forces borne by the

Achilles tendon (Sinclair, 2014; Sinclair et al. 2019) and the tibiofemoral joint (Sinclair et al. 2018b). However, it is important to recognise that the conclusions drawn from the aforementioned investigations were based upon results obtained from novice users of minimal footwear. Indeed, Tam et al. (2017) proposed that in acute investigations of minimal footwear, runners do not sufficiently alter their running mechanics sufficiently to reduce the vertical loading rate. Therefore, it can be concluded that the overall evidence that minimal footwear is able to attenuate the biomechanical factors linked to the aetiology of chronic pathologies is currently insufficient. As such, with regards to minimal footwear, runners must select footwear based on the findings from acute studies conducted on runners who are unaccustomed to using minimal footwear. Therefore, it can be concluded that further investigation of running biomechanics between minimal and conventional footwear in those who habitually wear minimal and conventional footwear is warranted.

Furthermore, previous analyses concerning the biomechanical differences between minimal and conventional footwear, have adopted inverse-dynamic driven modelling-based approaches to quantify lower extremity musculoskeletal loading (Sinclair et al., 2019). However, joint torques are representative of global indices of joint loading, and therefore are not representative of localized joint loading (Herzog et al. 2003). Substantial developments in musculoskeletal modelling have been made in recent years, allowing indices of skeletal muscle forces; muscle kinematics and joint reaction forces be obtained through musculoskeletal simulation analyses (Delp et al. 2007). This approach may be more effective than traditional inverse-dynamic based methods and allows a more detailed examination of the specific parameters linked to the aetiology of chronic pathologies to be undertaken. Such approaches have not yet been utilized to explore biomechanical differences between minimal and conventional running shoes in 
There has yet to be a published investigation examining differences in running biomechanics between minimal and conventional footwear in those who habitually wear minimal and conventional footwear. Therefore, the aim of the current investigation was to examine running biomechanics in minimal and conventional footwear in those who habitually wear minimal and conventional footwear, with reference to the biomechanical mechanisms linked to the aetiology of chronic pathologies, using a musculoskeletal simulation-based analysis.

\section{Methods}

Participants

\section{Ten male conventional footwear users (henceforth termed non-habitual minimal footwear} users) (age $27.67 \pm 5.57$ years, height $1.71 \pm 0.03 \mathrm{~m}$ and body mass $68.76 \pm 4.78 \mathrm{~kg}$ ) and ten male habitual minimal footwear users (henceforth termed habitual minimal footwear users) (age $33.50 \pm 4.58$ years, height $1.75 \pm 0.04 \mathrm{~m}$ and body mass $71.74 \pm 7.74 \mathrm{~kg}$ ) volunteered to take part in this study. Participants were required to complete a minimum of $35 \mathrm{~km}$ per week of training. To be considered a habitual minimal footwear user, volunteers were required to have been training exclusively in minimal footwear for a minimum period of 24 months in footwear scoring $\geq 75$ on the minimalist index described by Esculier et al. (2015). The procedure utilized for this investigation was approved by a university ethical committee (REF 637). All runners were free from musculoskeletal pathology at the time of data collection and provided written informed consent in accordance with the principles outlined in the Declaration of Helsinki. 
125 The footwear used during this study consisted of New Balance, 1260 v2 (New Balance, Boston, 126 Massachusetts, United States; henceforth termed conventional) and Vibram Five-Fingers, ELX 127 (Vibram, Albizzate, Italy; henceforth termed minimal) (Figure 1). The conventional footwear had an average mass of $0.285 \mathrm{~kg}$, heel thickness of $25 \mathrm{~mm}$ and a heel drop of $14 \mathrm{~mm}$ and minimal an average mass of $0.167 \mathrm{~kg}$, heel thickness of $7 \mathrm{~mm}$ and a heel drop of $0 \mathrm{~mm}$. The footwear were also scored using the minimalist index of Esculier et al. (2015), and the conventional footwear received a score of 20 and minimal a score of 92 .

@@@FIGURE 1 NEAR HERE@@@

Procedure

136 Participants ran at $4.0 \mathrm{~m} / \mathrm{s}( \pm 5 \%)$, striking an embedded piezoelectric force platform (Kistler Instruments Ltd., Winterthur, Switzerland) with their right (dominant) foot. Running velocity was monitored using infrared timing gates (Newtest, Oy Koulukatu, Finland). The stance phase was delineated as the duration over which $20 \mathrm{~N}$ or greater of vertical ground reaction force (GRF) was applied to the force platform. Runners completed five successful trials in each footwear condition. The order that participants ran in each footwear condition was counterbalanced. Kinematic and GRF data were synchronously collected. Kinematic data were captured at $250 \mathrm{~Hz}$ via an eight-camera motion analysis system (Qualisys Medical AB, Goteburg, Sweden). Dynamic calibration of the motion capture system was performed before each data collection session. 
Body segments were modelled in 6 degrees of freedom using the calibrated anatomical systems technique (Cappozzo et al. 1995). To define the anatomical frames of the thorax, pelvis, thighs, shanks and feet retroreflective markers were placed at the C7, T12 and xiphoid process landmarks and also positioned bilaterally onto the acromion process, iliac crest, anterior superior iliac spine (ASIS), posterior super iliac spine (PSIS), medial and lateral malleoli, medial and lateral femoral epicondyles, greater trochanter, calcaneus, first metatarsal and fifth metatarsal. Carbon-fibre tracking clusters comprising of four non-linear retroreflective markers were positioned onto the thigh and shank segments. In addition to these, the foot segments were tracked via the calcaneus, first metatarsal and fifth metatarsal, the pelvic segment was tracked using the PSIS and ASIS markers and the thorax segment was tracked using the T12, C7 and xiphoid markers. Static calibration trials were obtained in each footwear allowing for the

\section{anatomical markers to be referenced in relation to the tracking markers/ clusters.}

To measure axially directed accelerations at the tibia, an accelerometer (Biometrics ACL 300, Gwent United Kingdom) sampling at $1000 \mathrm{~Hz}$ was used. The device was mounted onto a piece of lightweight carbon-fibre material using the protocol outlined by Sinclair et al. (2013a). The accelerometer was attached securely to the distal anterio-medial aspect of the tibia in alignment with its longitudinal axis, $0.08 \mathrm{~m}$ above the medial malleolus. Strong non-stretch adhesive tape was placed over the device and leg to avoid overestimating the acceleration due to tissue artefact (Sinclair et al. 2013a).

\section{Processing}

Dynamic trials were digitized using Qualisys Track Manager (Qualisys Medical AB, Goteburg, Sweden) in order to identify anatomical and tracking markers then exported as C3D files to Visual 3D (C-Motion, Germantown, MD, USA). All data were linearly normalized to $100 \%$ 
of the stance phase. GRF data and marker trajectories were smoothed with cut-off frequencies of $50 \mathrm{~Hz}$ at $12 \mathrm{~Hz}$ respectively, using a low-pass Butterworth 4th order zero lag filter. In addition, the tibial acceleration signal was filtered using a $60 \mathrm{~Hz}$ Butterworth zero lag 4th order low pass filter (Sinclair et al. 2013a). Kinematics of the hip, knee and ankle were quantified using an $\mathrm{XYZ}$ cardan sequence of rotations (where $\mathrm{X}$ is flexion-extension; $\mathrm{Y}$ is ab-adduction and is $\mathrm{Z}$ is internal-external rotation). In addition, tibial internal rotation kinematics were also calculated in accordance with Eslami et al. (2007). All force parameters throughout were normalized by dividing by bodyweight (BW).

In accordance with the protocol of Addison \& Lieberman, (2015), an impulse-momentum modelling approach was utilized to calculate effective mass (\% BW), which was quantified in accordance with the below equation:

$$
\text { Effective mass }=\text { vertical GRF integral } /(\Delta \text { foot vertical velocity }+ \text { gravity } * \Delta \text { time })
$$

The impact peak was defined firstly in non-habitual runners when wearing conventional footwear, as the first peak in vertical GRF. In habitual runners and non-habitual runners wearing minimal footwear where no impact peak was expected, according to the protocols of Lieberman et al. (2010) and Sinclair et al. (2018a) we defined the position of the impact peak at the same relative position, which was shown to be $11.87 \%$ of the stance phase. The time (ms) to impact peak ( $\triangle$ time) was quantified as the duration from footstrike to impact peak. The vertical GRF integral $(\mathrm{BW} \cdot \mathrm{ms})$ during the period of the impact peak was calculated using a trapezoidal function. The change in foot vertical velocity ( $\triangle$ foot vertical velocity) was determined as the instantaneous vertical foot velocity averaged across the 10 frames prior to 
the impact peak (Sinclair et al. 2018a). The velocity of the foot was quantified using the centre of mass of the foot segment in the vertical direction, within Visual 3D (Sinclair et al. 2018a).

\section{Loading rate $(\mathrm{BW} / \mathrm{s})$ was also was also extracted by obtaining the peak increase in vertical} GRF between adjacent data points using the first derivative function within Visual 3D and the peak tibial acceleration $(\mathrm{g})$ was extracted as the highest positive acceleration peak during the stance phase. The strike index was calculated as the position of the centre of pressure location at footstrike, relative to the total length of the foot (Squadrone et al. 2015). A strike index of 0-33\% denotes a rearfoot, $34-67 \%$ a midfoot and $68-100 \%$ a forefoot strike pattern. Finally, limb stiffness during running was quantified using a mathematical spring-mass model (Blickhan, 1989). Limb stiffness (BW/m) was calculated from the ratio of the peak normalized vertical GRF to the maximum vertical compression of the leg spring which was calculated as the change in limb length from footstrike to minimum length during the stance phase (Farley \& Morgenroth, 1999). Limb length was quantified as the vertical height of the proximal end of the thigh segment within Visual 3D.

Following this, data during the stance phase were exported from Visual 3D into OpenSim 3.3 software (Simtk.org). Two validated musculoskeletal models were used to process the biomechanical data both of which were scaled to account for the anthropometrics of each runner. The first with 12 segments, 19 degrees of freedom and 92 musculotendon actuators (Lerner et al. 2015) was used initially to estimate lower extremity joint forces. As muscle forces are the main determinant of joint compressive forces (Herzog et al. 2003), muscle kinetics were quantified using static optimization in accordance with Steele et al. (2012). Compressive patellofemoral, medial/ lateral tibiofemoral, ankle and hip joint forces were calculated via the 
joint reaction analyses function using the muscle forces generated from the static optimization process as inputs. Furthermore, patellofemoral stress $(\mathrm{KPa} / \mathrm{kg})$ was quantified by dividing the patellofemoral force by the contact area. Patellofemoral contact areas were obtained by fitting a polynomial curve to the sex specific data of Besier et al. (2005), who estimated patellofemoral contact areas as a function of the knee flexion angle using MRI. Finally, Achilles tendon forces were estimated in accordance with the protocol of Almonroeder et al. (2013), by summing the muscle forces of the medial gastrocnemius, lateral, gastrocnemius, and soleus muscles.

In addition, patellofemoral, medial/ lateral tibiofemoral, ankle, hip and Achilles tendon instantaneous load rates (BW/s and $\mathrm{KPa} / \mathrm{BW} / \mathrm{s})$ were also extracted by obtaining the maximum increase in force/ stress between adjacent data points using the first derivative function in Visual

3D. Finally, the integral of the hip, tibiofemoral, ankle, patellofemoral and Achilles tendon forces $(\mathrm{BW} \cdot \mathrm{s})$ and stresses $(\mathrm{KPa} / \mathrm{BW} \cdot \mathrm{s})$ during the stance phase were calculated using a trapezoidal function.

Running in minimal footwear has been shown to alter step length during running, which increases the number of footstrikes necessary to run a set distance. We therefore estimated the total impulse per kilometre $(\mathrm{BW} \cdot \mathrm{km})$ by multiplying these parameters by the number of steps required to run a kilometre. The number of steps required to complete one kilometre was quantified using the step length (m), which was determined by taking the difference in the horizontal position of the foot centre of mass between the right and left legs at footstrike.

The second model also had twelve segments, 23 degrees of freedom and 92 muscle-tendon actuators and was adapted from the generic OpenSim gait2392 model to include the iliotibial band (Foch et al. 2013). The iliotibial band itself was included within the gait2392 model but 
as a muscle with only a passive contractile component and an optimal muscle fiber length of zero (Foch et al. 2013). Iliotibial band kinematics during the stance phase were calculated via the muscle analyses function within OpenSim and iliotibial band strain (\%) was calculated by dividing the change in length of the band during stance and dividing by its resting length at each time frame. In addition, the strain rate $(\% / \mathrm{s})$ was calculated as the change in strain between adjacent data points. The resting length of the iliotibial band was determined as its length during the static calibration trial (Hamill et al. 2008). Peak iliotibial band strain and strain rate were measured at the instance of peak knee flexion during stance (Hamill et al. 2008).

Statistical analyses

Following data processing, compressive joint forces (hip, patellofemoral, medial tibiofemoral and lateral tibiofemoral), Achilles tendon loading and three-dimensional kinematics during the entire stance phase were temporally normalized using linear interpolation to 101 data points. Differences across the entire stance phase were examined using 1-dimensional statistical parametric mapping (SPM) with MATLAB 2017a (MATLAB, MathWorks, Natick, USA), in accordance with Pataky et al. (2016), using the source code available at http://www.spm1d.org/. Differences as a function of both FOOTWEAR (FOOTWEAR conventional or minimal) and GROUP (GROUP - habitual or non-habitual) were examined

For discrete parameters that could not be examined using SPM (joint integral, joint loading rate, joint integral per kilometre, step length, instantaneous load rate, strike index, limb stiffness, tibial accelerations, iliotibial band strain, iliotibial band strain rate and effective mass), means and standard deviations were calculated for each condition. Differences in discrete biomechanical parameters were examined using 2 (FOOTWEAR - conventional of 
minimal) x 2 (GROUP- habitual or non-habitual) mixed ANOVAs, Effect sizes were calculated

271 using partial eta ${ }^{2}\left(\mathrm{p \eta}^{2}\right)$. In the event of a significant interaction, simple main effects tests were

272 adopted. Discrete statistical actions were conducted using SPSS v25.0 (SPSS Inc., Chicago,

273 USA). Statistical significance was accepted at the $\mathrm{P} \leq 0.05$ level.

275 Results

@@@TABLE 1 NEAR HERE@@@

Lower extremity external loading, strike index and step length

For effective mass there was a significant FOOTWEAR*GROUP interaction $\left(\mathrm{P}=0.01, \mathrm{p} \eta^{2}=\right.$

0.31). Simple main effects tests showed that effective mass was larger in the conventional

running shoes compared to minimal in habitual runners $\left(\mathrm{P}=0.01, \mathrm{p}^{2}=0.53\right)$ but there were no

significant differences between footwear in non-habitual runners $\left(\mathrm{P}=0.26, \mathrm{p} \eta^{2}=0.11\right)$. In

addition, when wearing minimal footwear, effective mass was significantly greater in non-

habitual runners compared to habitual $\left(\mathrm{P}<0.001, \mathrm{p \eta}^{2}=0.61\right)$ but there were no differences

between habitual and non-habitual runners when running in conventional footwear $(\mathrm{P}=0.50$,

$\left.\mathrm{p} \eta^{2}=0.03\right)($ Table 1$)$.

For loading rate there was also a significant FOOTWEAR $*$ GROUP interaction $\left(\mathrm{P}=0.002, \mathrm{p}^{2}\right.$

$=0.41$. Simple main effects tests showed that loading rate was significantly larger in the

minimal footwear compared to conventional in non-habitual runners $\left(\mathrm{P}=0.004, \mathrm{p}^{2}=0.63\right)$ but

there was no significant difference between footwear in habitual runners $\left(\mathrm{P}=0.94, \mathrm{p} \eta^{2}<0.001\right)$. 
habitual runners compared to habitual $\left(\mathrm{P}<0.001, \mathrm{p \eta}^{2}=0.52\right)$ but there were no differences when

running in conventional footwear $\left(\mathrm{P}=0.06, \mathrm{p}^{2}=0.19\right)$ (Table 1).

296

297 For peak tibial accelerations, there was a significant FOOTWEAR*GROUP interaction

$\left(\mathrm{P}=0.005, \mathrm{p \eta} \eta^{2}=0.36\right)$. Simple main effects tests showed that tibial accelerations were

significantly larger in minimal footwear compared to conventional in non-habitual runners

$\left(\mathrm{P}=0.03, \mathrm{p}^{2}=0.42\right)$ but there was no significant difference between fotowear in habitual

runners $\left(\mathrm{P}=0.09, \mathrm{p}^{2}=0.29\right)$. In addition, when wearing minimal footwear, tibial accelerations

were significantly greater in non-habitual compared to habitual runners $\left(\mathrm{P}<0.001, \mathrm{p \eta}^{2}=0.57\right)$

but there were no differences between habitual and non-habitual runners in conventional

footwear $\left(\mathrm{P}=0.20, \mathrm{p}^{2}=0.09\right)($ Table 1$)$.

305

306

307

For limb stiffness there was a significant FOOTWEAR*GROUP interaction $\left(\mathrm{P}=0.04, \mathrm{p}^{2}=\right.$

0.21). Simple main effects tests showed that limb stiffness was greater in minimal compared to conventional footwear in non-habitual runners $\left(\mathrm{P}<0.001, \mathrm{p \eta}^{2}=0.57\right)$ but there were no differences between footwear when running in conventional footwear $\left(\mathrm{P}=0.20, \mathrm{p \eta}^{2}=0.09\right)$ (Table 1).

311

312 For strike index there was a main effect of FOOTWEAR $\left(\mathrm{P}=0.002, \mathrm{p} \eta^{2}=0.36\right)$, which showed 313 that the strike position was more anterior in minimal footwear. In addition, there was also a 314 main effect of GROUP $\left(\mathrm{P}=0.007, \mathrm{p}^{2}=0.34\right)$, which indicated that the strike was also more anterior in habitual runners (Table 1).

317 For step length there was a significant FOOTWEAR*GROUP interaction $\left(\mathrm{P}=0.04, \mathrm{p} \eta^{2}=0.20\right)$. 318 Simple main effects tests showed that step length was significantly larger in conventional 
compared to minimal footwear in habitual runners $\left(\mathrm{P}=0.001, \mathrm{p}^{2}=0.72\right)$ but there was no

difference between footwear in non-habitual runners $\left(\mathrm{P}=0.70, \mathrm{p}^{2}=0.02\right)$. In addition, when

wearing minimal footwear compared to conventional, step length was significantly greater in

non-habitual runners $\left(\mathrm{P}=0.02, \mathrm{p \eta}^{2}=0.28\right)$ but there were no differences between habitual and

non-habitual runners when running in conventional footwear $\left(\mathrm{P}=0.11, \mathrm{p} \eta^{2}=0.14\right)$ (Table 1$)$.

Joint loading

For medial tibiofemoral loading rate there was a significant FOOTWEAR*GROUP interaction

$\left(\mathrm{P}<0.001, \mathrm{p}^{2}=0.76\right)$. Simple main effects tests showed that the loading rate was significantly

larger in the conventional compared to minimal footwear in habitual runners $\left(\mathrm{P}=0.001, \mathrm{p} \eta^{2}=\right.$

0.91) but significantly greater in minimal compared to conventional footwear in non-habitual

runners $\left(\mathrm{P}=0.005, \mathrm{p}^{2}=0.61\right)$. In addition, when wearing minimal footwear, medial

tibiofemoral loading rate was significantly greater in non-habitual compared to habitual runners

$\left(\mathrm{P}=0.02, \mathrm{p}^{2}=0.26\right)$ but in conventional footwear was significantly greater in habitual

compared to non-habitual runners $\left(\mathrm{P}=0.04, \mathrm{p}^{2}=0.21\right)$ (Table 1$)$.

For the integral of patellofemoral joint force, there was a main effect of FOOTWEAR $(\mathrm{P}=0.03$, $\left.\mathrm{p} \eta^{2}=0.25\right)$, which was shown to be larger in conventional footwear (Table 1).

338 For the integral of Achilles tendon force, there was a main effect of FOOTWEAR $\left(\mathrm{P}=0.02, \mathrm{p} \eta^{2}\right.$ $339=0.27$, which was shown to be larger in minimal footwear. In addition, there was a main effect 340 for GROUP $\left(\mathrm{P}=0.002, \mathrm{p}^{2}=0.42\right)$, which indicated that the Achilles tendon integral was greater 341 in habitual runners (Table 1). For the Achilles tendon integral per kilometre, there was a main 
342 effect of FOOTWEAR $\left(\mathrm{P}=0.004, \mathrm{p}^{2}=0.38\right)$, which was shown to be larger in minimal

343 footwear. In addition, there was a main effect for GROUP $\left(\mathrm{P}=0.002, \mathrm{p} \eta^{2}=0.41\right)$, which

344 indicated that the Achilles tendon integral was greater in habitual runners (Table 2).

346 For the ankle integral per kilometre, there was a main effect for GROUP $\left(\mathrm{P}=0.02, \mathrm{p} \eta^{2}=0.27\right)$, which indicated that the ankle integral was greater in habitual runners (Table 2).

Iliotibial band kinematics

350

For iliotibial band strain rate, there was a main effect for GROUP $\left(\mathrm{P}<0.001, \mathrm{p} \eta^{2}=0.52\right)$, which indicated that the strain rate was greater in non-habitual runners (Table 1).

Statistical parametric mapping - joint loading

Minimal footwear was associated with increased Achilles tendon force compared to conventional running shoes in the first $20 \%$ of the stance phase in both habitual and nonhabitual runners (Figure 2ab).

359 Conventional footwear was associated with increased hip flexion compared to minimal from $20-40 \%$ of the stance phase in habitual runners (Figure 2c). Conventional footwear was also associated with increased knee flexion compared to minimal from 40-60\% of the stance phase

362 in both habitual and non-habitual runners (Figure 2de). In additional, minimal footwear 
compared to conventional was associated with increased tibial and knee internal rotation during from $20-60 \%$ of the stance phase in habitual runners (Figure 3ab). Furthermore, it was revealed that the ankle exhibited increased plantarflexion in minimal footwear from $0-5 \%$ of the stance phase in both habitual and non-habitual runners (Figure 3cd). Finally, in conventional footwear compared to minimal, habitual runners were similarly associated with increased plantarflexion from $0-5 \%$ of the stance phase (Figure $3 e$ ).

@@@FIGURE3 NEAR HERE@@@

\section{Discussion}

The aim of the current investigation was to examine differences in running biomechanics between minimal and conventional footwear, in those who habitually wear minimal and conventional footwear. To the authors knowledge, this is the first quantitative comparison of these footwear in habitual and non-habitual minimal footwear users using a musculoskeletal simulation and SPM based approach.

The kinematic analysis using SPM of the sagittal plane ankle angle aligned with the discrete analysis of the strike index, supports previous investigations in that minimal footwear transferred the footstrike to a more anterior position in both habitual and non-habitual runners (Squadrone et al. 2015; Sinclair et al. 2019). Furthermore, in support of previous analyses the findings from this study also showed that habitual minimal footwear users similarly were associated with a significantly more anterior footsrike position in relation to non-habitual runners (Larson et al. 2014). It is important to contextualize the strike index values observed in both conditions, as regardless of which footwear condition was utilized non-habitual runners 
maintained a rearfoot strike pattern and habitual runners adopted a midfoot contact position. This supports proposition of Tam et al. (2017) that in acute investigations non-habitual runners

For the indices of external loading, in agreement with previous analyses this investigation showed that tibial accelerations and loading rates were found to be greater in minimal footwear in non-habitual runners (Sinclair et al. 2013ab) and in non-habitual runners when wearing minimal footwear (Lieberman et al. 2010). As non-habitual runners adopted a rearfoot strike pattern when wearing minimal footwear, it was expected that both effective mass and limb stiffness were also increased when non-habitual runners adopted minimal footwear. It is proposed that the increases in external loading indices were mediated by the corresponding changes in effective mass and limb stiffness, which have been shown previously to be positively related to the magnitude of the both tibial accelerations and loading rate (Sinclair et al. 2018a). As tibial accelerations/ loading rates were increased in non-habitual runners using minimal footwear, these observations may be clinically meaningful. Given the proposed association between tibial accelerations/ loading rates and the aetiology of chronic injuries (Davis et al. 2004), this study indicates that non-habitual runners wearing minimal footwear are at increased risk from impact related injuries.

Although no differences were revealed using SPM, the discrete analysis showed that the patellofemoral force integral was significantly larger in conventional footwear in both habitual and non-habitual groups. This finding concurs with those observed previously by Sinclair, (2014), Sinclair et al. (2016) and Bonacci et al. (2014) who showed significant reductions in patellofemoral loading when running in minimal footwear. The discrete and SPM based analyses showed that minimal footwear transferred the footstrike to a more anterior position 
and also reduced the extent of peak knee flexion in both habitual and non-habitual groups. It

414 is proposed that these observations are responsible for the reductions in patellofemoral loading as previous analyses have shown that the function of the knee joint as an energy absorber is reduced when there is an increased plantarflexion involvement (Sinclair \& Selfe, 2015). Importantly, excessive patellofemoral joint loading is considered a key mechanism linked to the aetiology of pain symptoms in active individuals (Ho et al. 2012). Therefore, the findings from the current investigation indicate that in both habitual and non-habitual runners, minimal footwear may be effective in attenuating the biomechanical parameters linked to the aetiology of patellofemoral pain.

In addition, it was revealed via the discrete analysis, that the loading rate at the medial aspect of the tibiofemoral joint was larger in the conventional footwear in habitual runners and in minimal footwear in non-habitual runners. This supports those of Sinclair et al. (2018b) who showed in non-habitual runners, that minimal footwear increased the loading rate at the medial aspect of the knee joint. This observation indicates that the loading rate at the medial tibiofemoral joint was statistically larger when runners performed in their non-preferred footwear condition. Because the loading rate at the medial knee has been cited as important predictor of radiographic knee osteoarthritis, the findings from this investigation indicate that runners are at increased risk when running in their non-preferred footwear condition without

\section{habituation (Morgenroth et al. 2014).}

Furthermore, this investigation showed using both SPM and discrete analyses that Achilles tendon loading indices were significantly larger in minimal footwear and in habitual runners collectively. This observation concurs with previous investigations (Sinclair, 2014, Sinclair et 
comparative literature examining the mechanics of the Achilles tendon in habitual minimal

footwear users. Importantly, the current study also showed that habitual runners were associated

with enhanced Achilles tendon loading compared to non-habitual users. It is proposed that the

mechanism responsible for these observations is the more anterior footsrike position in minimal

footwear and in habitual users, which served to enhance triceps surae muscle forces during the

eccentric aspect of the stance phase (Almonroeder et al. 2013). This observation may be

clinically important, as the initiation of Achilles tendinopathy is believed to be mediated

through repeated and excessive loads experienced by tendon itself without sufficient rest in

between loading exposures (Selvanetti et al. 1997). However, Davis et al. (2017) postulate that greater tendon loading in habituated runners may instigate the stimulus required for tendon hypertrophy and enhanced stiffness within the muscle-tendon unit necessary for the storage and release of elastic energy. Anrsten et al. (2017) support this notion as they showed that habitual minimal footwear users were associated with greater tendon cross sectional area and increased stiffness.

454 Finally, the current study also importantly showed that iliotibial band strain rate was greater in non-habitual runners. This finding may be clinically important as modelling investigations suggest that increased strain rate is the biomechanical risk factor linked to the aetiology of

457 iliotibial band syndrome (Hamill et al. 2008). The main mechanical difference (irrespective of footwear) between groups, was the adoption of a midfoot strike pattern in habitual minimal footwear users compared to non-habitual. Therefore, the findings from this study lend support to the proposition of Lalonde (2013) that a rearfoot landing should be avoided for the prevention of iliotibial band syndrome in runners, although further aetiological investigations 
transitioning to minimal footwear may be beneficial for runners in that they are able to attenuate their risk from iliotibial band syndrome.

A potential limitation to the current study that should be acknowledged is that only male runners were examined. Females have been shown to exhibit distinct external loading kinetics (Ferber et al. 2003), lower extremity kinematics (Sinclair et al. 2012, Ferber et al. 2003), limb stiffness (Sinclair et al. 2016), patellofemoral (Sinclair \& Selfe, 2015) and Achilles tendon (Greenhalgh \& Sinclair, 2014), parameters compared to male runners. This therefore suggests that further investigation of minimal footwear in habitual users using a female sample is warranted before comprehensive conclusions can be drawn. Furthermore, the efficacy of musculoskeletal simulation analyses depends on the fidelity of the primary neuromusculoskeletal model used to 2011). Therefore, there is considerable scope for future analyses to address and improve upon

these limitations, in order to provide more accurate and valid musculoskeletal simulations.

In conclusion, the biomechanics of minimal and conventional footwear have received widespread research attention. However, there has not been quantitative comparison of these footwear in habitual and non-habitual minimal footwear users using a musculoskeletal simulation and SPM based approach. This study revealed that minimal footwear mediated a more anterior contact position in both groups, although non-habitual runners still adopted a rearfoot strike pattern. In addition, minimal footwear increased tibial accelerations, loading rates and medial tibiofemoral loading rates in non-habitual runners and decreased patellofemoral loading in both habitual and non-habitual groups. Finally, Achilles tendon 
loading indices were larger in minimal footwear and in habitual runners whereas iliotibial band strain rate was reduced in habitual runners. Therefore, this study highlights firstly the importance of transitioning to minimal footwear and also indicates that post transition they may be effective in attenuating the biomechanical mechanisms linked to the aetiology of many chronic injuries.

\section{References}

1. Addison BJ, Lieberman DE. Tradeoffs between impact loading rate, vertical impulse and effective mass for walkers and heel strike runners wearing footwear of varying stiffness. J Biomech. 2015; 48: 1318-1324.

2. Almonroeder T, Willson JD, Kernozek TW. The effect of foot strike pattern on Achilles tendon load during running. Annal Biomed Eng. 2013; 41: 1758-1766.

3. Besier TF, Draper CE, Gold GE, Beaupré GS, Delp SL. Patellofemoral joint contact area increases with knee flexion and weight- bearing. J Orthop Res; 23; 345-350.

4. Blickhan R. The spring-mass model for running and hopping. J Biomech. 1989; 22: $1217-1227$.

5. Bonacci J, Vicenzino B, Spratford W, Collins P. Take your shoes off to reduce patellofemoral joint stress during running. Br J Sports Med. 2014; 48: 425-428.

6. Cappozzo A, Catani F, Leardini A, Benedeti MG, Della CU. Position and orientation in space of bones during movement: Anatomical frame definition and determination. Clin Biomech. 1995; 10: 171-178.

7. Davis IS. The re-emergence of the minimal running shoe. J Orthop Sports Phys Ther. 2014; 44: 775-784.

8. Davis I, Milner CE, Hamill, J. Does Increased Loading during Running Lead to Tibial Stress Fractures? A Prospective Study. Med. Sci. Sports Exerc 2004, 36, S58, 
9. Delp SL, Anderson FC, Arnold AS, Loan P, Habib A, John CT, Thelen DG. OpenSim: open-source software to create and analyze dynamic simulations of movement. IEEE Trans Biomed Eng. 2007; 54: 1940-1950.

10. Esculier JF, Dubois B, Dionne CE, Leblond J, Roy JS. A consensus definition and rating scale for minimalist shoes. J Foot Ankle Res. 2015; 8: 42-46.

11. Eslami M, Begon M, Farahpour N, Allard P. Forefoot-rearfoot coupling patterns and tibial internal rotation during stance phase of barefoot versus shod running. Clin Biomech. 2007; 22: 74-80.

12. Farley CT, Morgenroth DC. Leg stiffness primarily depends on ankle stiffness during human hopping. J Biomech. 1999; 32: 267-273.

13. Ferber R, Davis IM, Williams DS. Gender differences in lower extremity mechanics during running. Clin Biomech. 2003; 18: 350-357.

14. Foch E, Reinbolt JA, Zhang S, Milner CE. Association between iliotibial band syndrome status and running biomechanics in women. Proceedings of American Society of Biomechanics. 2013; Omaha, NE.

15. Greenhalgh A, Sinclair J. Comparison of Achilles tendon loading between male and female recreational runners. J Human Kinet. 2014; 44: 155-159.

16. Herzog W, Longino D, Clark A. The role of muscles in joint adaptation and degeneration. Langenbeck Arch Surg. 2003; 388: 305-315.

17. Hespanhol LC, Van Mechelen W, Postuma E, Verhagen E. Health and economic burden of running-related injuries in runners training for an event: A prospective cohort study. Scand J Med Sci Sports. 2016; 26: 1091-1099.

18. Hamill J, Miller R, Noehren B, Davis I. A prospective study of iliotibial band strain in runners. Clin Biomech. 2008; 23: 1018-1025. 
19. Histen K, Arntsen J, L'Hereux L, Heeren J, Wicki B, Saint S, Joseph MF. Achilles tendon properties of minimalist and traditionally shod runners. J Sport Rehab. 2017; 26: $159-164$.

20. Ho KY, Blanchette MG, Powers CM. The influence of heel height on patellofemoral joint kinetics during walking. Gait Posture. 2012; 36: 271-275.

21. Hollander K, Argubi-Wollesen A, Reer R, Zech A. Comparison of minimalist footwear strategies for simulating barefoot running: a randomized crossover study. PloS one. 2015; 10: e0125880.

22. Lalonde F. Iliotibial Band Syndrome: Noninvasive Solutions for Runners. ACSM's Health Fitness Journal. 2013; 17: 9-13.

23. Lee DC, Pate RR, Lavie CJ, Sui X, Church TS, Blair SN. Leisure-time running reduces all-cause and cardiovascular mortality risk. J Am Coll Cardiol. 2014; 64: 472-481.

24. Lerner ZF, DeMers MS, Delp SL, Browning RC. How tibiofemoral alignment and contact locations affect predictions of medial and lateral tibiofemoral contact forces. $\mathbf{J}$ Biomech. 2015; 48: 644-650.

25. Lieberman DE, Venkadesan M, Werbel WA, Daoud AI, D'andrea S, Davis IS, Pitsiladis Y. Foot strike patterns and collision forces in habitually barefoot versus shod runners. Nature. 2010; 463: 531-535.

26. Larson P. Comparison of foot strike patterns of barefoot and minimally shod runners in a recreational road race. J Sport Health Sci. 2014; 3: 137-142.

27. Morgenroth DC, Medverd JR, Seyedali M, Czerniecki JM. The relationship between knee joint loading rate during walking and degenerative changes on magnetic resonance imaging. Clin Biomech. 2014; 29: 664-670. 
28. Pataky TC, Robinson MA, Vanrenterghem J. Region-of-interest analyses of onedimensional biomechanical trajectories: bridging OD and 1D theory, augmenting statistical power. Peer J. 2016; 4: 2652-2664.

29. Selvanetti A, Cipolla M, Puddu G. Overuse tendon injuries: basic science and classification. Oper Tech Sports Med. 1997; 5: 110-117.

30. Seth A, Sherman M, Reinbolt JA, Delp SL. OpenSim: a musculoskeletal modeling and simulation framework for in silico investigations and exchange. Procedia IUTAM. 2011; 2: 212-232.

31. Sinclair J, Greenhalgh A, Edmundson CJ, Brooks D, Hobbs SJ. Gender differences in the kinetics and kinematics of distance running: implications for footwear design. Int $\mathrm{J}$ Sport Sci Eng. 2012; 6: 118-128.

32. Sinclair J, Greenhalgh A, Edmundson CJ, Brooks D, Hobbs SJ. The influence of barefoot and barefoot-inspired footwear on the kinetics and kinematics of running in comparison to conventional running shoes. Footwear Sci. 2013a; 5: 45-53.

33. Sinclair J, Hobbs SJ, Currigan G, Taylor PJ. A comparison of several barefoot inspired footwear models in relation to barefoot and conventional running footwear. Comp Exerc Physiol. 2013b; 9: 13-21.

34. Sinclair J. Effects of barefoot and barefoot inspired footwear on knee and ankle loading during running. Clin Biomech. 2014; 29: 395-399.

35. Sinclair J, Selfe J. Sex differences in knee loading in recreational runners. J Biomech. 2015; 48: 2171-2175.

36. Sinclair J, Richards J, Selfe J, Fau-Goodwin J, Shore H. The influence of minimalist and maximalist footwear on patellofemoral kinetics during running. J Appl Biomech. 2016; 32: 359-364. 
37. Sinclair J, Shore HF, Taylor PJ, Atkins S. Sex differences in limb and joint stiffness in recreational runners. Hum Mov. 2016; 16: 137-141.

38. Sinclair J, Stainton P, Hobbs SJ. Effects of barefoot and minimally shod footwear on effective mass-Implications for transient musculoskeletal loading. Kinesiology. 2018a; 50: $165-171$.

39. Sinclair J, Butters B, Stainton P. Acute effects of barefoot and minimalist footwear on medial tibiofemoral compartment loading during running: A statistical parametric mapping approach. J Hum Kinet. 2018b; 65: 35-40.

40. Sinclair J, Brooks D, Stainton P. Biomechanical effects of a lightweight, sock-style minimalist footwear design during running: a musculoskeletal simulation and statistical parametric mapping approach. Footwear Sci. 2019; 11: 71-83.

41. Snyder RA, Koester MC, Dunn WR. Epidemiology of stress fractures. Clin Sports Med. $2006 ; 25: 37-52$.

42. Squadrone R, Rodano R, Hamill J, Preatoni E. Acute effect of different minimalist shoes on foot strike pattern and kinematics in rearfoot strikers during running. J Sports Sci. 2015; 33: 1196-1204.

43. Steele KM, DeMers MS, Schwartz MH, Delp SL. Compressive tibiofemoral force during crouch gait. Gait Posture. 2012; 35: 556-560.

44. Tam N, Darragh IA, Divekar NV, Lamberts RP. Habitual minimalist shod running biomechanics and the acute response to running barefoot. Int J Sports Med. 2017; 38: $770-775$.

45. Taunton JE, Ryan MB, Clement DB, McKenzie DC, Lloyd-Smith DR, Zumbo BD. A retrospective case-control analysis of 2002 running injuries. Br J Sports Med. 2002; 36: 95-101. 
625

626

627

628

629

630

631

46. van Gent BR, Siem DD, van Middelkoop M, van Os TA, Bierma-Zeinstra SS, Koes BB. Incidence and determinants of lower extremity running injuries in long distance runners: a systematic review. Br J Sports Med. 2007; 41: 469-480.

47. Van Ginckel A, Thijs Y, Hesar NGZ, Mahieu N, De Clercq D, Roosen P, Witvrouw E. Intrinsic gait-related risk factors for Achilles tendinopathy in novice runners: a prospective study. Gait Posture. 2009; 29: 387-391.

48. Warne JP, Kilduff SM, Gregan BC, Nevill AM, Moran KA, Warrington GD. A 4week instructed minimalist running transition and gait- retraining changes plantar pressure and force. Scand J Med Sci Sports. 2014; 24: 964-973.

49. Winkelmann ZK, Anderson D, Games KE, Eberman LE. Risk factors for medial tibial stress syndrome in active individuals: an evidence-based review. J Ath Train. 2016; 51: 1049-1052. 


\begin{tabular}{|c|c|c|c|c|c|c|c|c|c|}
\hline & \multicolumn{4}{|c|}{ Non-habitual } & \multicolumn{4}{|c|}{ Habitual } & \\
\hline & \multicolumn{2}{|c|}{ Conventional } & \multicolumn{2}{|c|}{ Minimal } & \multicolumn{2}{|c|}{ Conventional } & \multicolumn{2}{|c|}{ Minimal } & \\
\hline & Mean & $S D$ & Mean & $S D$ & Mean & $S D$ & Mean & $S D$ & \\
\hline Effective mass (\% BW) & 9.59 & 1.93 & 11.32 & 1.81 & 9.06 & 1.53 & 7.83 & 1.01 & $\mathrm{~B}, \mathrm{C}$ \\
\hline Loading rate $(\mathrm{BW} / \mathrm{s})$ & 154.36 & 69.86 & 293.00 & 126.14 & 105.97 & 27.20 & 105.44 & 48.95 & $\mathrm{~A}, \mathrm{~B}, \mathrm{C}$ \\
\hline Peak tibial acceleration $(\mathrm{g})$ & 8.16 & 2.04 & 9.54 & 1.90 & 7.06 & 1.60 & 6.35 & 0.86 & $\mathrm{~B}, \mathrm{C}$ \\
\hline Limb stiffness (BW/m) & 63.41 & 28.52 & 65.91 & 22.69 & 63.46 & 33.51 & 48.12 & 13.97 & $\mathrm{C}$ \\
\hline Iliotibial band strain $(\%)$ & 2.41 & 2.09 & 2.44 & 1.85 & 2.09 & 2.18 & 2.54 & 1.27 & \\
\hline Iliotibial band strain rate $(\% / \mathrm{s})$ & 42.87 & 14.67 & 42.96 & 12.71 & 30.30 & 7.37 & 28.32 & 8.06 & B \\
\hline Patellofemoral integral $(\mathrm{BW} \cdot \mathrm{s})$ & 0.29 & 0.08 & 0.26 & 0.08 & 0.31 & 0.13 & 0.28 & 0.10 & A \\
\hline Patellofemoral loading rate (BW/s) & 156.50 & 55.49 & 154.50 & 33.75 & 179.18 & 48.37 & 143.14 & 22.99 & \\
\hline $\begin{array}{c}\text { Patellofemoral stress integral } \\
(\mathrm{KPa} / \mathrm{BW} \cdot \mathrm{s})\end{array}$ & 0.56 & 0.14 & 0.52 & 0.13 & 0.59 & 0.21 & 0.55 & 0.18 & \\
\hline $\begin{array}{l}\text { Patellofemoral stress loading rate } \\
(\mathrm{KPa} / \mathrm{BW} / \mathrm{s})\end{array}$ & 323.28 & 125.29 & 326.40 & 81.24 & 375.92 & 117.61 & 302.65 & 59.30 & \\
\hline Achilles integral $(\mathrm{BW} \cdot \mathrm{s})$ & 0.65 & 0.07 & 0.71 & 0.05 & 0.71 & 0.05 & 0.79 & 0.12 & A, B \\
\hline Achilles loading rate (BW/s) & 153.96 & 43.34 & 179.34 & 67.96 & 179.34 & 67.96 & 148.14 & 38.75 & \\
\hline Ankle integral $(\mathrm{BW} \cdot \mathrm{s})$ & 1.21 & 0.12 & 1.30 & 0.12 & 1.30 & 0.12 & 1.33 & 0.19 & \\
\hline Ankle loading rate $(\mathrm{BW} / \mathrm{s})$ & 251.82 & 41.42 & 281.18 & 55.95 & 281.18 & 55.95 & 247.14 & 40.27 & \\
\hline Hip integral $(\mathrm{BW} \cdot \mathrm{s})$ & 1.34 & 0.16 & 1.31 & 0.09 & 1.31 & 0.09 & 1.25 & 0.13 & \\
\hline Hip loading rate $(\mathrm{BW} / \mathrm{s})$ & 276.22 & 41.21 & 291.88 & 82.86 & 291.88 & 82.86 & 260.00 & 123.79 & \\
\hline Medial tibiofemoral integral $(\mathrm{BW} \cdot \mathrm{s})$ & 0.86 & 0.10 & 0.83 & 0.06 & 0.83 & 0.06 & 0.85 & 0.12 & \\
\hline Medial tibiofemoral loading rate $(\mathrm{BW} / \mathrm{s})$ & 212.57 & 51.75 & 274.96 & 75.23 & 274.96 & 75.23 & 196.17 & 64.60 & $\mathrm{C}$ \\
\hline Lateral tibiofemoral integral $(\mathrm{BW} \cdot \mathrm{s})$ & 0.44 & 0.07 & 0.44 & 0.05 & 0.44 & 0.05 & 0.41 & 0.07 & \\
\hline Lateral tibiofemoral loading rate $(\mathrm{BW} / \mathrm{s})$ & 157.20 & 63.56 & 151.07 & 38.23 & 151.07 & 38.23 & 130.20 & 36.26 & \\
\hline Strike index $(\%)$ & 22.61 & 17.92 & 33.79 & 24.69 & 46.48 & 21.44 & 61.68 & 19.33 & $\mathrm{~A}, \mathrm{~B}$ \\
\hline $\begin{array}{ll}637 & \mathrm{~A}=\text { main effect of FOOTWEAR } \\
638 & \mathrm{~B}=\text { main effect of GROUP } \\
639 & \mathrm{C}=\text { FOOTWEAR } \mathrm{x} \text { GROUP interaction }\end{array}$ & & & & & & & & & \\
\hline
\end{tabular}

641

642

643

644

645

646 
Table 2: Discrete temporal biomechanical parameters (mean \pm standard deviations) as a function of

\begin{tabular}{|c|c|c|c|c|c|c|c|c|c|}
\hline & \multicolumn{4}{|c|}{ Non-habitual } & \multicolumn{4}{|c|}{ Habitual } & \\
\hline & \multicolumn{2}{|c|}{ Conventional } & \multicolumn{2}{|c|}{ Minimal } & \multicolumn{2}{|c|}{ Conventional } & \multicolumn{2}{|c|}{ Minimal } & \\
\hline & Mean & $S D$ & Mean & $S D$ & Mean & $S D$ & Mean & $S D$ & \\
\hline Step length (m) & 1.41 & 0.14 & 1.4 & 0.15 & 1.29 & 0.17 & 1.23 & 0.15 & $\mathrm{~A}, \mathrm{~B}, \mathrm{C}$ \\
\hline $\begin{array}{l}\text { Patellofemoral integral per kilometre m } \\
\text { (BW·km) }\end{array}$ & 543.91 & 163.20 & 493.74 & 160.51 & 646.21 & 300.30 & 612.77 & 253.39 & \\
\hline $\begin{array}{l}\text { Patellofemoral stress integral per } \\
\text { kilometre }(\mathrm{KPa} / \mathrm{BW} \cdot \mathrm{km})\end{array}$ & 1048.04 & 280.21 & 970.31 & 268.78 & 1203.71 & 494.77 & 1188.42 & 439.10 & \\
\hline Achilles integral per kilometre $(\mathrm{BW} \cdot \mathrm{km})$ & 1196.94 & 174.21 & 1328.26 & 134.48 & 1446.36 & 181.08 & 1697.98 & 361.64 & $\mathrm{~A}, \mathrm{~B}$ \\
\hline Ankle integral per kilometre $(\mathrm{BW} \cdot \mathrm{km})$ & 2255.40 & 334.19 & 2410.35 & 249.97 & 2637.91 & 428.70 & 2849.76 & 582.01 & $\mathrm{~B}$ \\
\hline Hip integral per kilometre $(\mathrm{BW} \cdot \mathrm{km})$ & 2507.87 & 504.79 & 2465.54 & 403.70 & 2672.95 & 391.66 & 2676.06 & 452.34 & \\
\hline $\begin{array}{l}\text { Medial tibiofemoral integral per } \\
\text { kilometre }(\mathrm{BW} \cdot \mathrm{km})\end{array}$ & 1608.00 & 298.37 & 1561.71 & 234.69 & 1694.68 & 239.98 & 1826.23 & 378.21 & \\
\hline $\begin{array}{l}\text { Lateral tibiofemoral integral per } \\
\text { kilometre }(\mathrm{BW} \cdot \mathrm{km})\end{array}$ & 815.75 & 191.45 & 826.17 & 133.47 & 902.91 & 173.35 & 875.81 & 201.87 & \\
\hline $\begin{array}{l}A=\text { main effect of FOOTWEAR } \\
B=\text { main effect of GROUP } \\
C=\text { FOOTWEAR x GROUP interact }\end{array}$ & & & & & & & & & \\
\hline
\end{tabular}

653

654

655

656

657

658

659

660

661

662

663

664

665

666

667 


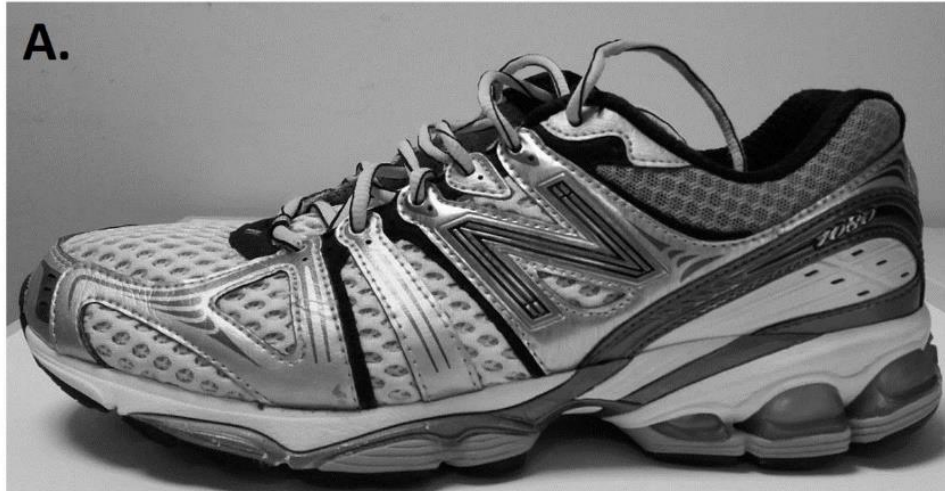

B.

670 Figure 1: Experimental footwear $(\mathrm{A}=$ conventional and $\mathrm{B}=$ minimal $)$. 

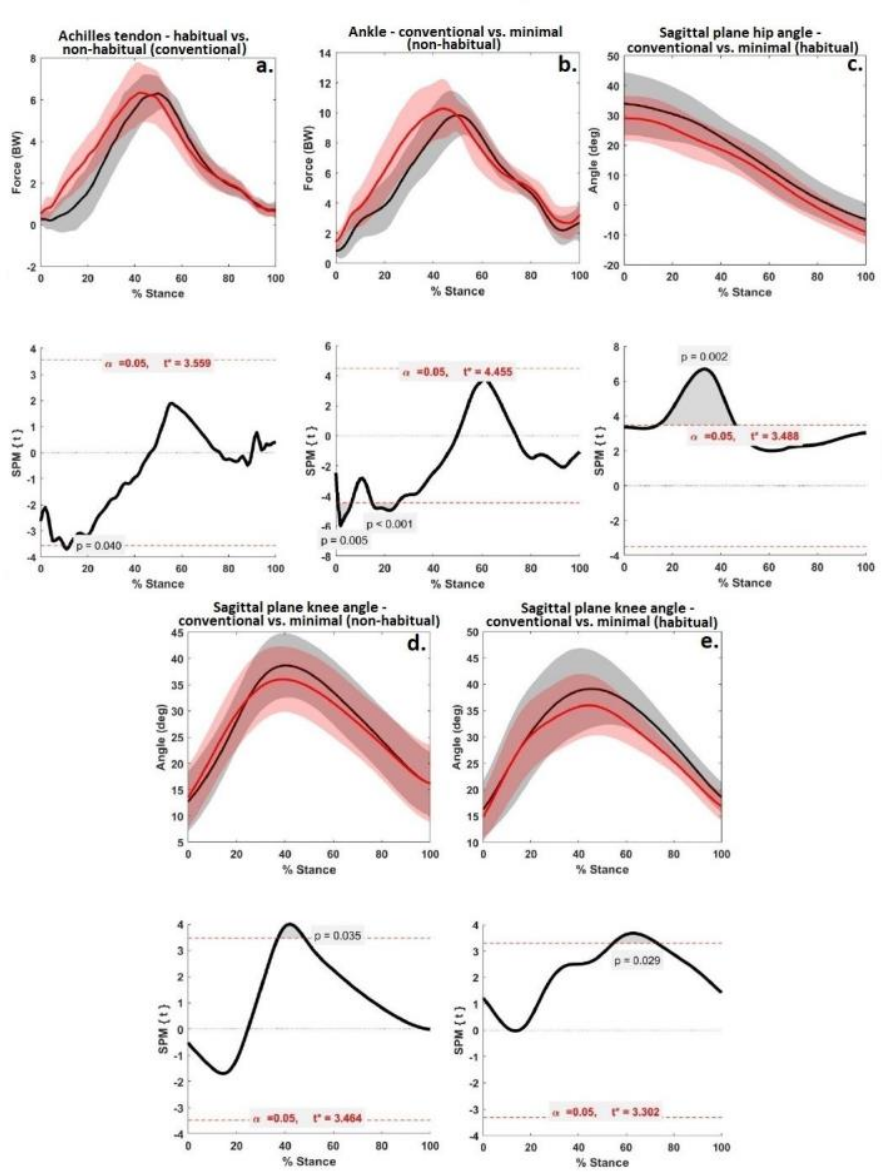

671

672 Figure 2: Statistical parametric mapping results of Achilles tendon and ankle forces in addition

673 to hip and knee kinematics (FOOTWEAR: black = conventional/ $\mathrm{red}=$ minimal \& GROUP:

674 black $=$ non-habitual/ red $=$ habitual $)$. 

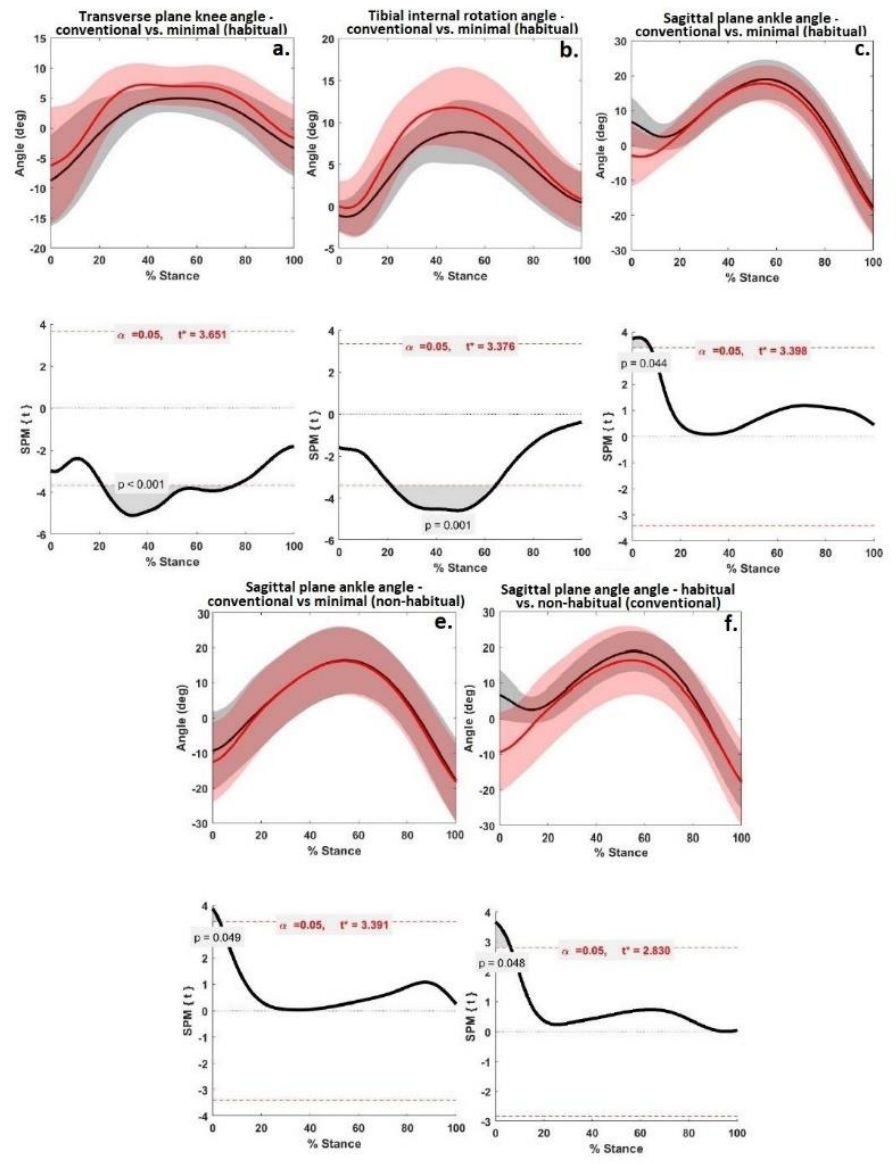

675

676 Figure 3: Statistical parametric mapping results of tibial internal rotation, knee and ankle

677 kinematics $($ FOOTWEAR: black $=$ conventional $/$ red $=$ minimal $\&$ GROUP: black $=$ non-

678 habitual/ red = habitual). 